\title{
Atomic layer deposition (ALD) for environmental protection and whisker mitigation of electronic assemblies
}

\author{
Caterina Soldano ${ }^{1} \cdot$ Mark A. Ashworth ${ }^{2} \cdot$ Geoffrey D. Wilcox ${ }^{2} \cdot$ Terho Kutilainen $^{3} \cdot$ Jussi Hokka $^{4} \cdot$ Jaan Praks $^{1}$. \\ Marko Pudas 5
}

Received: 10 June 2021 / Revised: 31 August 2021 / Accepted: 28 September 2021 / Published online: 18 October 2021

(c) The Author(s) 2021

\begin{abstract}
In this study, we demonstrate how metal-oxide thin-film conformal coatings grown by atomic layer deposition (ALD) can be exploited as an effective approach to mitigate tin whisker growth on printed circuit boards. First, we study the effect of different ALD coatings and process parameters on $\mathrm{Sn}-\mathrm{Cu}$-electroplated test coupons, by combining optical imaging and scanning electron microscopy and evaluating whisker distribution on the surface. On these samples, we found that one important parameter in mitigating whisker growth is the time interval between electroplating and the ALD coating process (pre-coat time), which should be kept of the order of few days (2, based on our results). Atomic layer-deposited coatings were also found to be effective toward whisker formation in different storage conditions. Furthermore, we show that ALD coating is also effective in limiting the need for outgassing of electronic assemblies (PCBAs), which is an additional stringent requirement for applications in space industry. Our experimental results thus demonstrated that atomic layer deposition is a suitable technique for aerospace applications, both in terms of degassing and whisker mitigation.
\end{abstract}

Keywords Tin whiskers $\cdot$ Mitigation $\cdot$ Conformal coating $\cdot$ Atomic layer deposition (ALD) $\cdot$ PCBA

\section{Introduction}

Tin whiskers currently represent an electrical reliability risk in the form of potential short circuits in electronic devices or source of disturbance in signal transmission, with strong impact in many fields ranging from automotive to motherboards, from space industry to consumer electronics. This risk, potentially, becomes even greater in space capsules,

Caterina Soldano

caterina.soldano@aalto.fi

Marko Pudas

marko.pudas@picosun.com

1 Department of Electronics and Nanoengineering, Aalto University, Espoo, Finland

2 Department of Materials, Materials Degradation Centre, Loughborough University, Loughborough, UK

3 Oy Poltronic Ab, Oulu, Finland

4 ESA-ESTEC, European Space Agency-European Space Research and Technology Centre, Noordwijk, The Netherlands

5 Picosun Oy, Masala, Finland automotive and aircrafts, which are subjected to multiple and severe thermal cycling and high humidity conditions [1] and where the electronics is required to function reliably for several years. Introducing a small percentage of lead to tin solder has traditionally been an effective approach in mitigating such effect. In the last 2 decades, several legislations have been introduced globally to ban or limit $\mathrm{Pb}$ incorporation in electronics devices (Restriction of Hazardous Substances-RoHS in Europe in 2006 [2], Electronic Waste Recycling Act-EWRA [3] in California in 2003), further supported by the need for a more environmentally conscious world (free of lead and other contaminants), and tin whisker growth has become again a significant issue in electronic devices. Small addition of other metals (i.e., silver and copper) can adjust the melting temperature and tune some of the properties required for the soldering process and aid long-term reliability; however, it does not preclude tin whisker growth. Although RoHS regulation allows for exceptions and exemptions such as space applications, the availability of tin-lead plated components is decreasing and fewer manufacturers maintain tin-lead soldering processes, as most of the commercial electronics industry is becoming lead-free. Tin whisker growth, which may occur 
spontaneously and unpredictably from electroplated Sn finishes and solder joints, can result in short circuits leading to electronics failures. According to the Joint Electronic Device Engineering Council (JEDEC) standard, a feature is classified as a whisker if it possesses an aspect ratio (length/ width) greater than 2, with length greater than $10 \mu \mathrm{m}$ [4]. Short circuits induced by whiskers may be permanent if the current is smaller than the melting current of the whisker, or intermittent if the current is sufficient to cause the whisker to melt (typically $>10 \mathrm{~mA} \mathrm{[5]).} \mathrm{In} \mathrm{some} \mathrm{cases,} \mathrm{whiskers} \mathrm{may}$ melt and bridge again or break loose and cause false signals or even short circuits with sensitive parts of the device. Airborne whiskers may also interfere with sensitive surfaces, such as those in optoelectronic equipment [6]. If the source provides sufficient current, a short circuit may result under vacuum conditions in the formation of a conductive plasma of metal ions, which may cause severe damage to the device and its surrounding structures through localized electrical arcing.

To date, the underlying mechanism for tin whisker growth has not been fully and completely understood [7, 8], although intensive research has been carried out for several decades now. An overall consensus on factors playing a fundamental role in whisker growth has been reached: (i) in-plane compressive stresses, caused by volumetric expansion following the $\mathrm{Sn}-\mathrm{Cu}$ intermetallic growth, providing the driving force for whiskers to grow [9], (ii) rapid grain boundary self-diffusion from the tin electroplate interior to the growing whisker [10], and (iii) a surface oxide layer which limits surface vacancy sources, thus preventing diffusion and corresponding stress relief via diffusional processes [11]. In addition, several other factors have shown to influence whisker growth such as morphology and crystallographic structure of the intermetallic compound [12], mismatch in the coefficients of thermal expansion (CTE) causing stress during thermal cycling [13], elevated temperatures and high humidity conditions leading to corrosion [14], and applied external mechanical stress [15]. It is also here important to recall that morphologies and physical properties of the $\mathrm{Sn}$ layers such as thickness, grain size, and crystallographic structure [13], as well as other factors such as current load [16, 17] and electrostatic forces [18], also contribute to whisker formation.

Different methods have been proposed and effectively used to mitigate whisker formation and growth including thermal annealing [19], creating porous Sn coatings [20], and inserting a metallic interlayer (i.e., Ni) with low diffusivity for copper from the substrate [21] and conformal coatings [22] of various types. In particular, conformal coatings further offer an effective barrier toward the external environment (in terms of humidity, particles, solvents, liquid, and gaseous impurities), and at the same time, if the coating is insulating, this can dielectrically isolate the whisker from surrounding metallic surfaces. The latter will limit, fully or partially, the short, in the case of physical contact with adjacent metallic surfaces, where the dielectric layer will offer greater resistance to electrical breakdown.

Several studies in space technology research have shown, for example, that urethane conformal coatings as well as other acrylic wet coating (e.g., silicone and epoxy) are capable of successfully mitigating tin whisker growth [23], in some cases for up to several years [24]. However, any site left un-coated is a potential source for tin whisker growth, as shown in the 1000 days study by NPL [25]. Among many organic materials, parylene has been proposed to be an effective material in protecting electronic devices, in particular against moisture, which causes a variation in PCB's thermo-mechanical properties and thus its ability to function as designed (WVTR, water vapor transmission rate as low as $0.02 \mathrm{~g} / \mathrm{m}^{2} /$ day [26]). Deposited by chemical vapor deposition at room temperature, parylene is capable of coating and penetrating "deeply" any surface, leading to an ultraresistant pinhole-free hydrophobic protective coating. The low-temperature processing does not introduce any mechanical stress into the substrate, one of the concurring causes for whiskers formation and growth; furthermore, the coating is chemically inert and can sustain large temperature variations without modification to its properties. On the other hand, parylene is not reworkable and it has been reported to have delamination issues on several materials (e.g., ceramic materials) [27]; it was also shown to fail at tin whisker mitigation in $1000-4000 \mathrm{~h} 85^{\circ} \mathrm{C} / 85 \% \mathrm{RH}$ tests [28].

Atomic layer deposition (ALD) is a mature thin-film deposition process applied at different stages of integrated circuit (IC) manufacture. ALD is a gas-phase coating method used to produce ultra-thin films of high uniformity and conformality, and is based on surface-controlled and self-saturating adsorption reactions between gaseous precursors and the substrate. The growth process leads to a precise control of film thickness and results in highly conformal coatings. Atomic layer deposition takes place in vacuum $(0.1-10 \mathrm{mbar}$ in commercially available equipment and typically in the range of temperature $40-400{ }^{\circ} \mathrm{C}$, and, for some materials, it can be performed at room temperature and on plastic substrates [29]. Recently, ALD has been used for corrosion protection in several industrial and commercial applications [30], and has been proposed as a potential approach for whisker growth mitigation. ALD thin films have reported values for WVTR which are orders of magnitude lower than for example parylene $\left(<5 \times 10^{-5} \mathrm{~g} / \mathrm{m}^{2} /\right.$ day [31] $)$, along with significantly lower estimated cost of ownership (cost of equipment, materials, and operating expenses). In this study, a processing temperature of $125^{\circ} \mathrm{C}$ was identified, since this temperature ensures the removal of water during the layerby-layer coating. In addition, the self-limiting nature of ALD produces extremely smooth, continuous, and pinhole-free 
films, because no un-coated surface sites are left behind during film growth. This is extremely important for example in thin-film encapsulation (TFE) to improve diffusion barrier properties [32]. Single-element materials and alloys/ compounds as well as alternating monolayer structures can be fabricated with extreme precision, where optimization of these layers requires engineering thicknesses and structures. Laminate-type structures have previously been shown to provide very effective and efficient protection against corrosion [33] and offer the potential to improve the flexibility of the coating. For a more in-depth description of the ALD process, we refer the reader to more dedicated and detailed literature [34].

In this study, we investigate the potentials of metal-oxide thin film coatings grown by atomic layer deposition as a mitigation strategy against tin whisker growth. We also address if ALD coatings processes are effective in limiting the need for degassing in Printed Circuit Board Assemblies (PCBAs), hence to assess if our proposed whisker mitigation approach is also suitable for electronic devices used in space applications.

\section{Experimental section}

$\mathrm{Sn}-\mathrm{Cu}$ coatings were deposited from a commercial Sn electroplating bath containing a brightener and modified by the addition of $10 \mathrm{mmol}^{-1}$ copper sulfate and operated according to parameters previously studied (e.g., $2 \mu \mathrm{m}$-thick coatings deposited at a current density of $10 \mathrm{~mA} \mathrm{~cm}^{-2}$ ) and reported elsewhere [35]. Test coupons $(0.4 \mathrm{~mm}$ thick, 99.9\% purity, Advent Research Materials) had dimensions of $20 \mathrm{~mm} \times 40 \mathrm{~mm}$ with an electroplated area of about $20 \mathrm{~mm} \times 20 \mathrm{~mm}$ on one side only. The electroplating process was performed on the same site (at Picosun Oy, Masala) to fully control the time interval between $\mathrm{Sn}-\mathrm{Cu}$ deposition and ALD coating. Control samples were kept and analyzed for each electroplated batch. The density of whiskers on the surface has been measured by evaluating the number of whiskers present at 25 different locations uniformly distributed across the sample surface by optical microscopy using a $20 \times$ objective lens. This corresponds to an individual analyzed area of $\sim 0.57 \mathrm{~mm}^{2}$, leading to a total analyzed area of approximately $14.25 \mathrm{~mm}^{2}$ (out of an available $400 \mathrm{~mm}^{2}$ ) for each sample. Only filamenttype whiskers and large eruptions with an aspect ratio $>10$ were counted toward the present study, while structures similar to nodules and small eruptions with lower aspect ratios $(<2)$ were not included. For whiskers growing at an angle to the substrate surface, focus stacking has been used to measure their apparent length while combining multiple images, taken at different focus distances, into a single image with enough depth of field to cover the entire whisker length. This method has been very useful in assessing the characteristic dimensions of free-standing nano- and micro-structures. Average values of whisker densities here presented have been measured using at least three test samples for ALD-coated coupons and two unprocessed control samples (where available). Part of the imaging was carried on using a scanning electron microscope (SEM); SEM micrographs were typically obtained at $5 \mathrm{kV}$ to minimize charging effects and to reduce the possibility of damage to the ALD coating without the need of a Au/Pd or carbon coat.

Thermal cycling (200 cycles in the range from $+85{ }^{\circ} \mathrm{C}$ to $-40{ }^{\circ} \mathrm{C}$ ) and elevated temperature/humidity testing were carried out in a Memmert HCP153 environmental chamber at $55{ }^{\circ} \mathrm{C} / 85 \%$ relative humidity for two samples from each test batch. Weiss climatic test-chamber WKL $34 / 70$ was used to carry on thermal cycling $\left(+85^{\circ} \mathrm{C}\right.$ to $\left.-40{ }^{\circ} \mathrm{C}\right)$, with heating and cooling rates of $\sim{ }^{\circ} \mathrm{C} \mathrm{min}{ }^{-1}$ and 10 minutes dwelling time at each set temperature (in accordance with JESD22-A104D: Temperature Cycling [36]).

For bake-out tests, PCBs (Isola 370HR) were first cleaned according to the following procedure: immersion in IPA for 1 minute, rinse in IPA, and dry in air. The test equipment consisted of a vacuum chamber equipped with a temperature control and two quartz crystal monitors (QCMs) and were operated through a custom Labview software. Test samples were placed on hot plate providing uniform heating $\left(T=100^{\circ} \mathrm{C}\right)$; a hot cylinder was positioned surrounding the hotplate and was equipped with two disks at each end of the cylinder. Each of these four elements was driven by a separate controller and their temperatures were monitored by dedicated sensors. A cold plate was maintained at cryogenics temperatures $\left(-150^{\circ} \mathrm{C}\right)$ by means of liquid nitrogen during the test to trap the condensable outgassing products. Two QCMs were mounted on the cold plate. Preliminary tests were conducted on a blank sample to assess the minimum sensitivity of the experimental set-up.

\section{Results and discussion}

In this study, we report our findings on the effectiveness of ALD coatings as a mitigation strategy for whiskers growth. We demonstrate how ALD-grown thin films can control whisker growth on $\mathrm{Sn}-\mathrm{Cu}$-electroplated surfaces while investigating several metal oxides and process parameters, and how these affect the overall formation of whiskers. Each batch included five ALD-coated and two references (uncoated) test coupons.

\subsection{ALD process steps (presence of precursor and ozone in the process chamber)}

ALD coatings were deposited in Picosun P300 and R150 ALD reactors, at Picosun site facilities. During all coating processes, a silicon test wafer was included in the 
coating batch, and the thickness of the ALD film deposited on its surface was measured with an ellipsometer. Figure 1a shows the main features of an ALD coating cycle to deposit a metal-oxide film; precursor molecule chemically bonds with any available attachment sites to create a layer of reactant 1; next, a purge gas is used to flush any extra, unreacted, or incompletely reacted precursor from the system followed by oxidation upon exposure to a mixture of carrier gas and $\mathrm{H}_{2} \mathrm{O}$. A second purge step again removes unreacted species, resulting in a monolayer oxide film. The main parameters associated with these different steps include process temperature, ozone concentration, precursor, and chamber purging time. We refer the reader to one of our earlier works [37] for more details about the ALD process. Figure $1 \mathrm{~b}$ shows the effect of different pretreatments alone on a $50 \mathrm{~nm}$-thick ALD film (ALD1) in terms of subsequent whisker density after 2 and 4 months from ALD coating. Reference (untreated) samples are also included and labelled accordingly. Initially, we treated our test coupons according to the following:

a) Oxidizing (ox-only) and reducing gases (red.-only) only, instead of complete ALD pulses to assess if a strongly oxidizing environment can potentially lead to the formation of native oxide capable of preventing and/or limiting further whisker growth. Similarly, the effects of reducing gases on their own were studied.

b) Thermally treated (th.-only), at the process temperature $\left(125^{\circ} \mathrm{C}\right)$ and time for the ALD process. Previously, annealing processes have been suggested to introduce a delay in the whisker formation on tin-based surfaces [38].

In this case, our results show that ALD-coated samples present no tin whisker growth on the surface after $\sim 2$ months after the coating process (light pink); on the other hand, untreated test coupons (light blue) showed a large number of tin whiskers, with a relatively large standard deviation (25-35\%) most likely due to random areas being analyzed on the surface and the random nature of the whisker growth. Within our experimental error, no difference or correlation is found between the treatments.

Two treated reference test coupons have further undergone processing steps closely mimicking the ALD coating process (labelled as "O3" and "50 nm", indicating, respectively, the presence of ozone/precursor and ozone/precursor at the deposition temperature, both leading to $50 \mathrm{~nm}$ thick film). While the reference samples showed whisker densities generally higher than in the case of pre-treatments, however, given the larger error associated with our counting, no conclusive assessment can be made at this stage. ALDcoated samples (light pink) show no tin whiskers growth, except for only one sample showing seven whiskers, due possibly to the random selection of locations for analysis.

These samples were also analyzed again approximately 4 months after the initial ALD coating (dark blue and dark pink in Fig. 1b) and no whiskers were observed on any ALD-coated samples. Reference (un-coated) coupons exhibited a progressive increase in whisker density (20-140\% increase with respect to the previous measurement after $\sim 2$ months), with no specific correlation between initial density, storage time, and sample type. While a detailed study of whisker length variation as a function of our process parameters and storage time was beyond the scope of the present study, nevertheless, we observed that test coupons presented a few whiskers with lengths greater than $500 \mu \mathrm{m}$ after longer storage times (not shown).

Our results suggest that ALD coating is an effective strategy in mitigating tin whisker growth; we believe that this could be the consequence of reduced number of defect states (e.g., $\mathrm{Al}-\mathrm{Al}$ and $\mathrm{OH}$, leading to $\mathrm{Al}$ cluster formations, in the case of $\mathrm{Al}_{2} \mathrm{O}_{3}$ ) resulting from the large supply of oxygen atoms from the decomposition of $\mathrm{O}_{3}$ [39] and improved barrier capabilities against water vapor from the external environment [40].

\subsection{ALD coatings}

Coatings with different metal-oxide material composition and thicknesses (80-120 nm) were deposited on the samples within few hours after the $\mathrm{Sn}-\mathrm{Cu}$ electroplating (see Table 1). Here, ALD\# refers to Picosun proprietary ALD stacks, compatible and available with the Picosun P300 tool. All ALD-coated samples showed no whisker growth after 6 months, nor at the second measurement time of 25 months after ALD coating. Figure 2a shows the whisker density found on reference test coupons (no ALD coating), with values of density ranging from approximately $\sim 320$ to $\sim 1200$ whiskers $/ \mathrm{cm}^{2}$. Figure $2 \mathrm{~b}$ shows representative images of whiskers found on the surface of the reference un-coated test coupons after 6 months. The scale bar of $50 \mu \mathrm{m}$ is the same in all images. More than 25 months after the ALD coating process, no whiskers have been found on ALD-coated test coupons. This suggests that ALD coating is indeed an effective approach to mitigate (and possibly inhibit) tin whisker growth, independently on the material composition of the layer. These samples were transferred to Trelic Oy (Finland) for long-term study and this work is still ongoing.

\subsection{Pre-coat time-time interval between $\mathrm{Sn}-\mathrm{Cu}$ electroplating and ALD coating}

In this study, we have also investigated and assessed the effect of pre-coat time, which we define as the time interval between the $\mathrm{Sn}-\mathrm{Cu}$ electroplating of the test coupons 


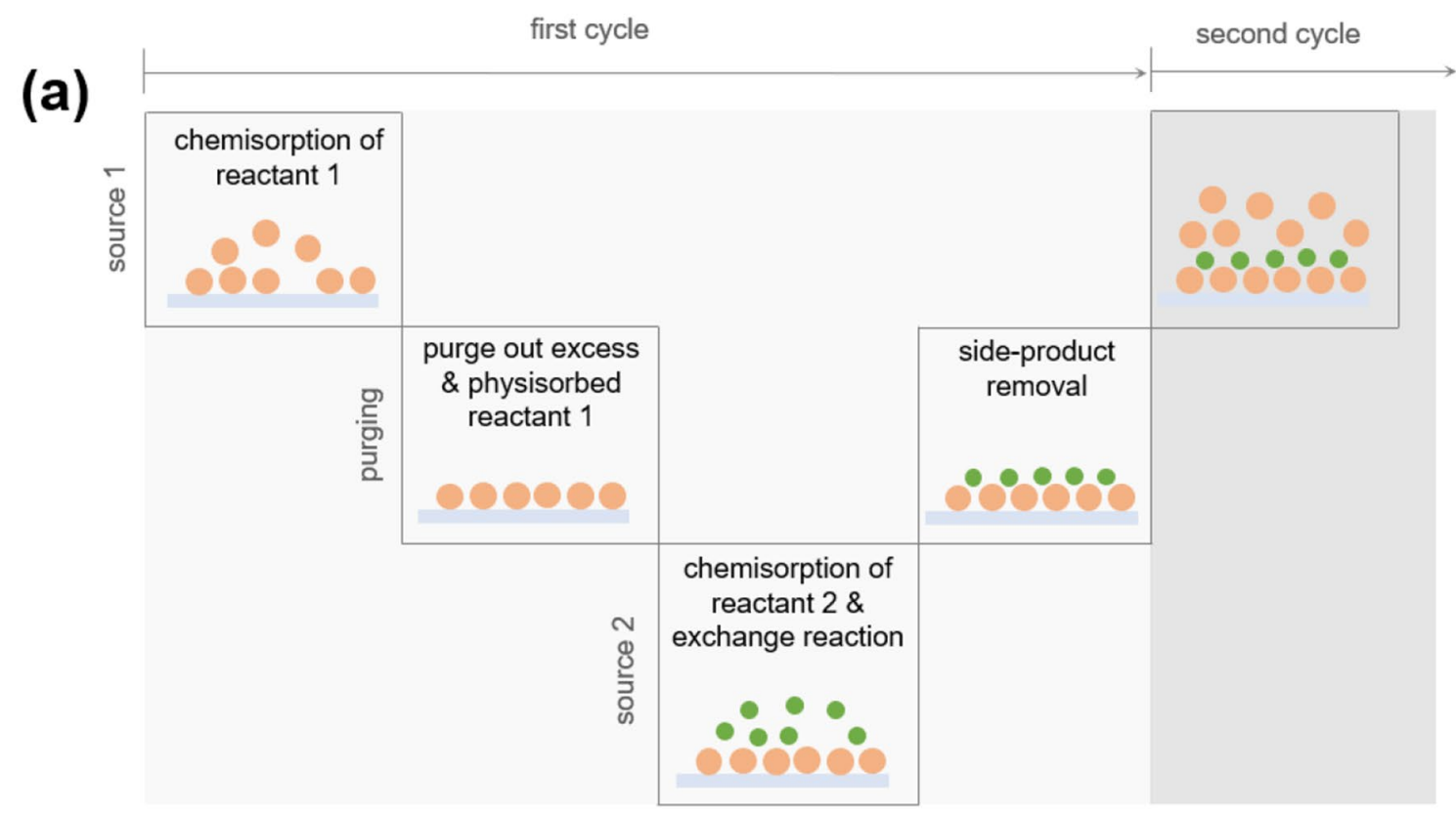

(b)

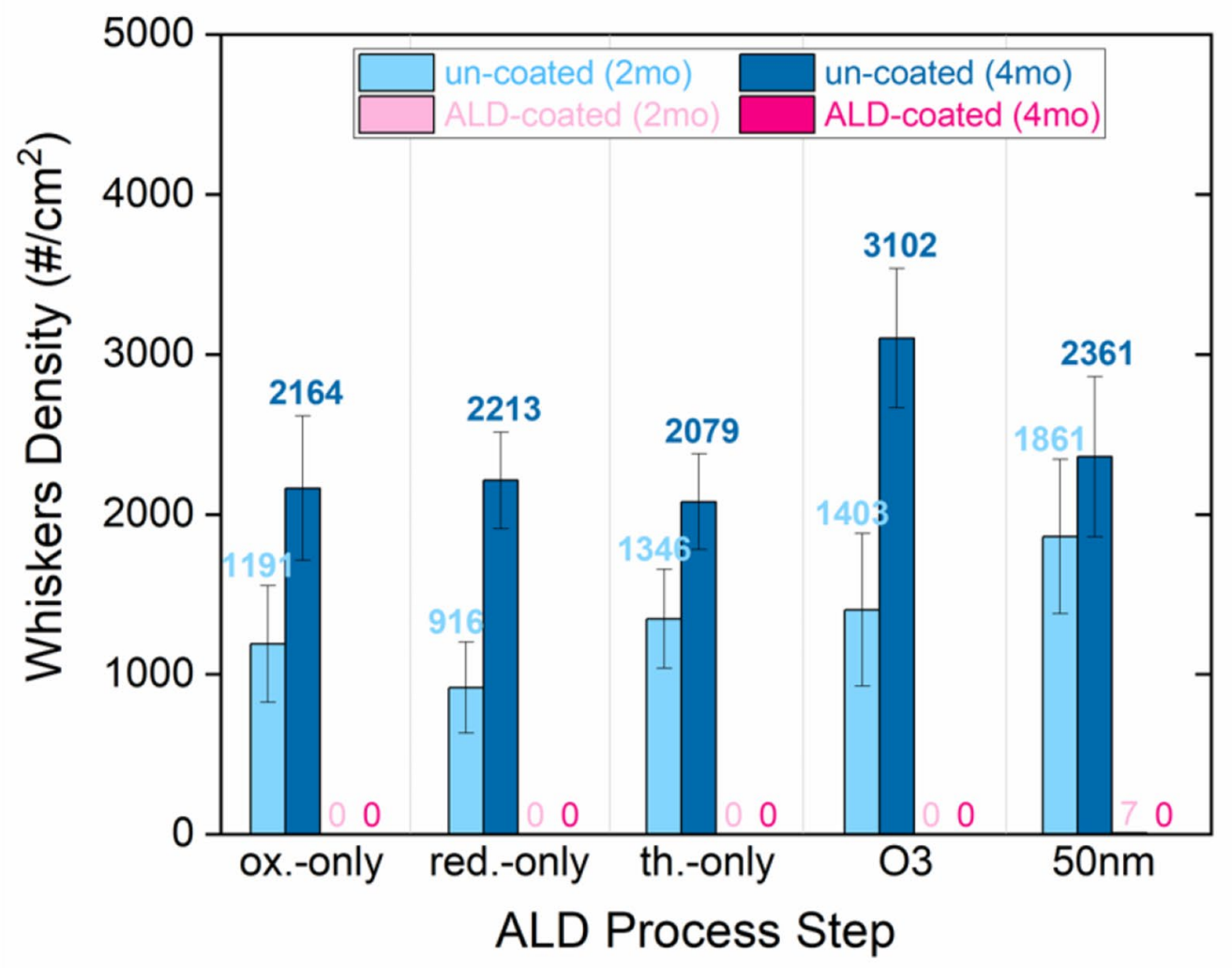

Fig. 1 Whisker growth with different pre-treatments and ALD process steps. a Schematics representing the four different steps occurring in one cycle of an ALD-coating process. (From left to right) precursor molecules chemically bond with any available attachment sites to create a reactant 1 rich containing monolayer; next, a purge gas is used to flush any extra, unreacted, or incompletely reacted precursor from the system followed by oxidation upon exposure to a mixture of carrier gas and $\mathrm{H}_{2} \mathrm{O}$. A second purge step again removes unreacted species, resulting in a monolayer oxide film. b Study of whisker density for reference samples (light blue after $\sim 2$ months and dark blue a second measurement after $\sim 4$ months from coating) and ALD-coated sample (ALD1: $50 \mathrm{~nm}$, light pink and dark pink after 2 and 4 months respectively) 
Table 1 Summary of the samples analyzed for each parameter investigated. Each batch includes five test coupons (ALD-coated) and two reference test coupons (un-coated) for a single parameter (see manuscript for more details)

\begin{tabular}{|c|c|c|c|c|c|}
\hline & Coating & Thickness (nm) & Storage $^{\mathrm{a}}$ & $\begin{array}{l}\text { Thermal cycling } \\
\left(85-40^{\circ} \mathrm{C}\right)\end{array}$ & $\begin{array}{l}\text { Storage condition } \\
\left(55^{\circ} \mathrm{C} / 85 \% \mathrm{RH}\right)\end{array}$ \\
\hline $\begin{array}{l}\text { ALD process steps (temperature, ozone, pre- } \\
\text { cursor in the reactor) }\end{array}$ & ALD1 & 50 & 3 & 1 & 1 \\
\hline Pre-coat time (few hours to 15 days) & ALD2 & 101 & 3 & 1 & 1 \\
\hline \multirow[t]{8}{*}{ Coatings (different materials and processes) } & ALD3 & 79.5 & 5 & - & - \\
\hline & ALD4 & 94.2 & 5 & - & - \\
\hline & ALD5 & 91 & 5 & - & - \\
\hline & ALD6 & 120 & 5 & - & - \\
\hline & ALD7 & 121 & 5 & - & - \\
\hline & ALD8 & 102.9 & 5 & - & - \\
\hline & ALD9 & 100 & 5 & - & - \\
\hline & ALD10 & 111.2 & 5 & - & - \\
\hline Bake-out (PCBA) & ALD11 & 80 & - & - & - \\
\hline
\end{tabular}

${ }^{a}$ Up to 25 months, as reported in the manuscript. Studies are still ongoing

and the subsequent ALD coating. Pre-coat times ranging from a few hours to 2 weeks have been investigated, with evaluation of whisker density carried out within 6 months of processing for all batches, to establish if this parameter is significant. Figure 3 shows the whisker density for test coupons as a function of pre-coat time. We found that whiskers were present only in samples which had been kept for about 15 days prior to the ALD coating (ALD2, coating thickness $101 \mathrm{~nm}$ ) and for which we found an average whisker density of approximately $465 \pm 256$ whiskers $/ \mathrm{cm}^{2}$. It is assumed that tin whiskers had started to grow prior to ALD coating. No whiskers were found on samples with shorter pre-coat times (up to 2 days). Correspondingly, reference samples (no ALD coating), monitored for similar "pre-coat" period, showed whiskers on the surface ranging from 1000 to $\sim 5000 / \mathrm{cm}^{2}$. We found no evidence of a clear correlation between whisker density and pre-coat time for our test coupons; however, in future work, it should be investigated in more detail to provide additional experimental data in the middle range, since populating the pre-coat time between 2 and 15 days will provide a more detailed insight into any possible relation between pre-coat time and whisker density. Results clearly demonstrate that the ALD-coating process itself results in a very effective mitigation of whisker growth provided that the pre-coat time is minimized. Whiskers found on the reference test coupons (no ALD coating) were typically $100 \mu \mathrm{m}$ or shorter, as shown by (b) optical images and (c) scanning electron micrographs. Longer whiskers were also present, but in very small numbers (not shown).

Experimental results on pre-coat time strongly suggest that whisker formation and growth are strongly related to the properties of the $\mathrm{Sn}-\mathrm{Cu}$ underlying layer, which supposedly undergoes relaxation and stress adjustment after electroplating. We believe that when the ALD is performed shortly after electroplating, those reconfiguration mechanisms are strongly limited, and thus, whiskers growth is prevented. It is in fact demonstrated that the surface morphology of the $\mathrm{Sn}-\mathrm{Cu}$-electroplated surfaces depends on several parameters such as composition of bath, current density, and coating thickness [41]. Furthermore, in many of our optical and SEM images, although not considered in the whisker counts, morphology analysis shows small eruptions and nodules on the substrates. The grain structure of the $\mathrm{Sn}-\mathrm{Cu}$ surface is also expected to induce additional stress, thus contributing to the formation of whiskers. This is also consistent with the dynamic process described for intermetallic compounds by Hou et al. [42], which have studied systematically the effect of the interfacial mobility, grain boundary mobility, grain boundary diffusion coefficient, and Sn grain structure on the growth kinetics and morphology of the intermetallic compounds. Although such a study is currently beyond the scope of the present work, we will address these issues in the future.

Finally, we also here note that ALD-coated samples (pre-coat time shorter than 2 days) do not present any whisker growth up to 45-50 days after coating, nor after approximately 25 months from the initial whisker investigation (not shown). Furthermore, Fig. 4 illustrates the elemental composition of whiskers on ALD-coated test coupons (ALD-coated 15 days after the electroplating) using energy-dispersive X-ray spectroscopy (EDX) microanalysis. This was carried out to assess if the whiskers were indeed present before, or had grown after the ALDcoating process itself. Figure $4 a$, b shows secondary electrons micrographs of different whiskers and protrusions on 
Fig. 2 Whisker density for different ALD coatings. a Whisker density study for $\mathrm{Sn}-\mathrm{Cu}$ coatings with (pink) and without (light blue) different ALD films approximately after 6 months from initial coating. It shows that ALD coatings appear to be an effective strategy in mitigating tin whisker growth. b Representative optical images of un-coated test coupons showing tin whisker growth on the surface (a)



(b)
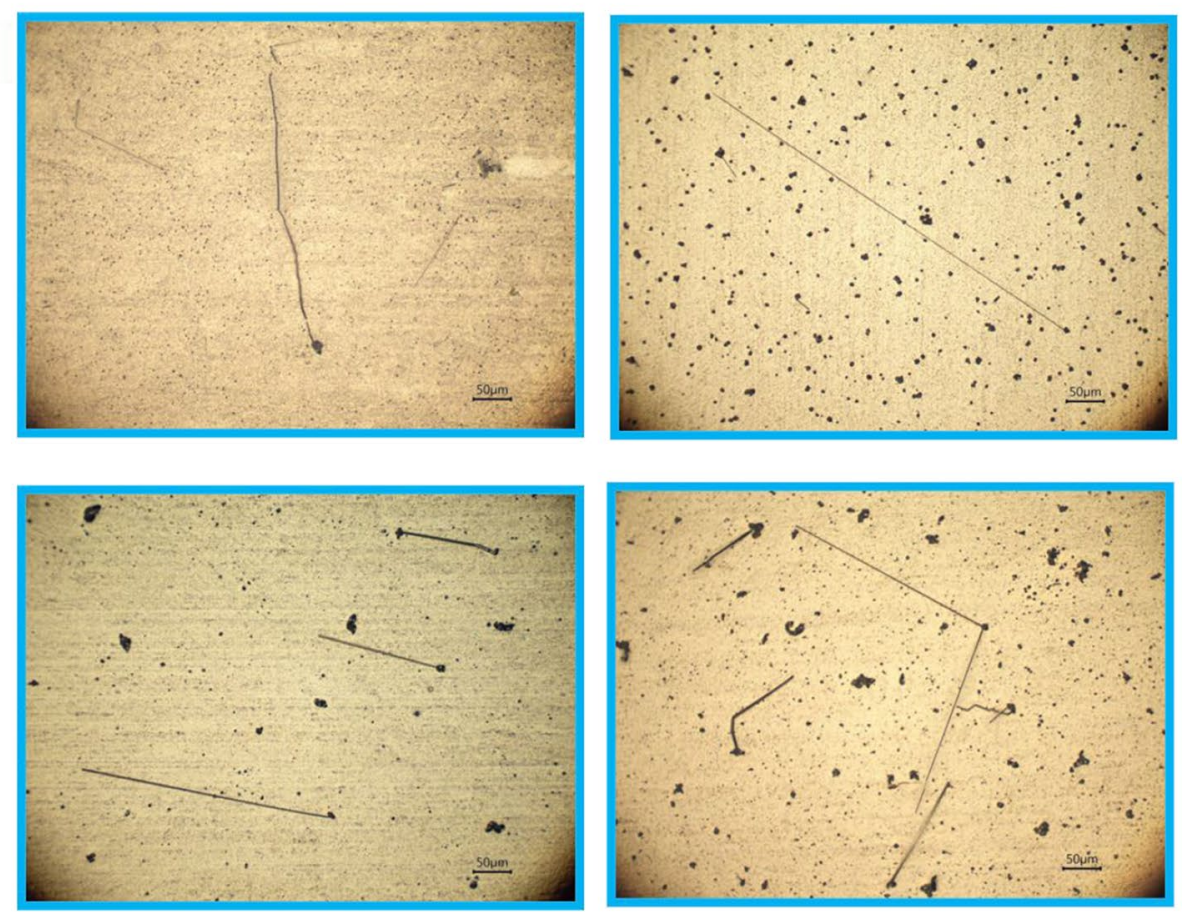

the ALD-coated test coupons, together with the labelled locations at which EDX spectra were acquired. A representative EDX spectrum (Fig. 4c, relative to site 1) displays the presence of $\mathrm{Sn}, \mathrm{Al}$, and $\mathrm{O}$, thus strongly suggesting that the ALD coating $\left(\mathrm{Al}_{2} \mathrm{O}_{3}\right)$ is still adhered to the tin, and conformally present around the site of the tin whiskers, demonstrating that the whisker was present before the
ALD coating. Figure $4 \mathrm{~d}$ summarizes the elemental composition for each of the sites as indicated in (a).

\subsection{Thermal cycling in the range $+85^{\circ} \mathrm{C} /-40^{\circ} \mathrm{C}$}

Thermal treatment is expected to delay tin whisker growth, since this process relieves stress; on the other hand, this has been shown to lead to the appearance of a large number 
Fig. 3 Whisker density as function of pre-coat time. a Whisker density as function of the time interval between $\mathrm{Sn}-\mathrm{Cu}$ electroplating and the ALDcoating process on test coupons. Experimental results show that pre-coat times shorter than 2 days ensure effective ALD coating and whisker mitigation. Optical (b) and scanning electron microscope (c) images showing representative whiskers found on the surface of the test coupon with a pre-coat time of 15 days

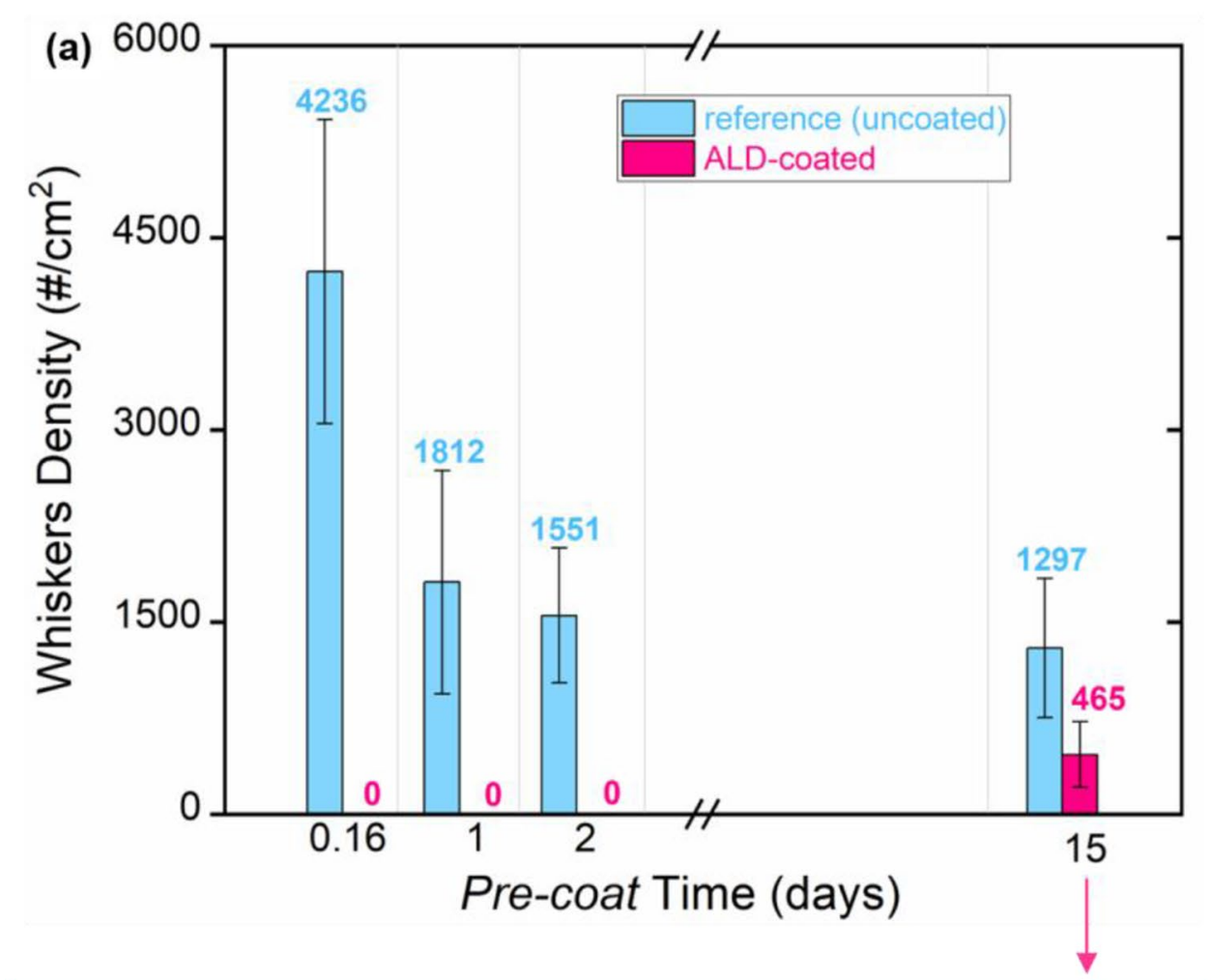

(b)
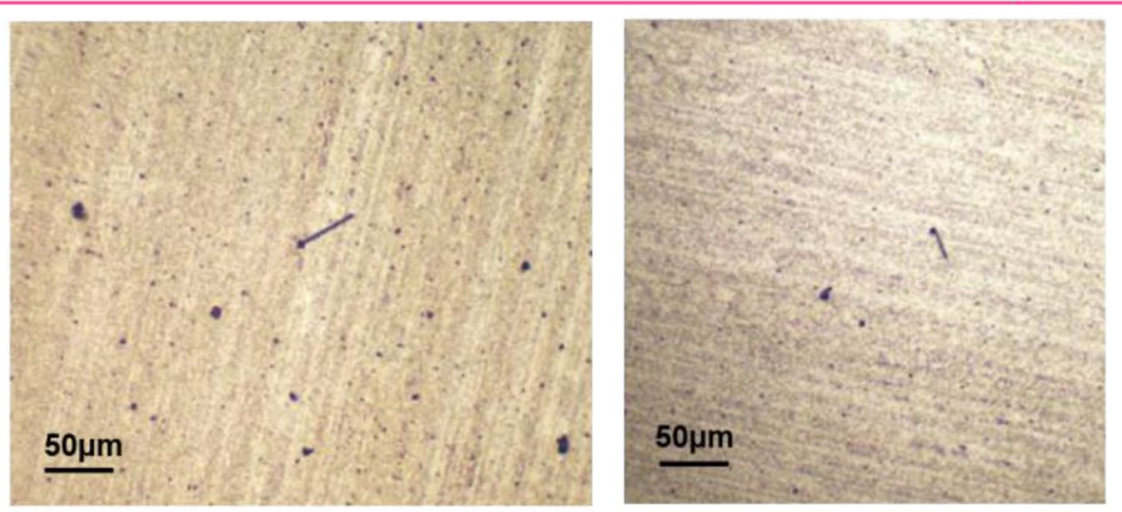

(c)
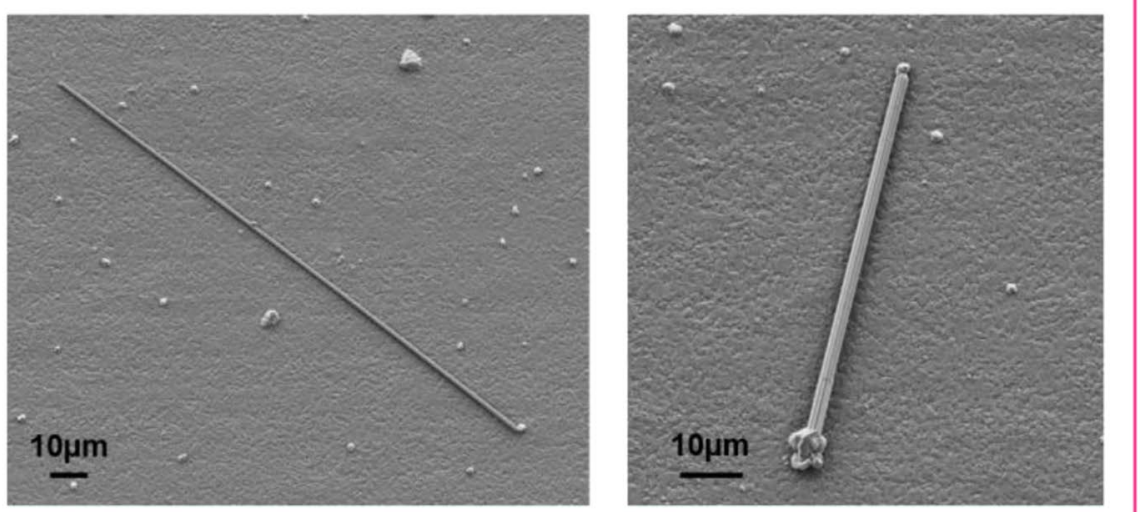

of micro-cracks, which can affect the overall reliability of solder joints [43, 44]. Two test coupons were selected from each batch from the "pre-coat" and "ALD process steps" studies; while one was stored in an environmental chamber at $55^{\circ} \mathrm{C} / 85 \% \mathrm{RH}$, one has undergone 200 cycles of thermal cycling in the range from $+85^{\circ} \mathrm{C}$ to $-40{ }^{\circ} \mathrm{C}$. An intermediate/partial analysis of coating integrity and whisker growth was performed after 100 cycles, which showed no evidence 


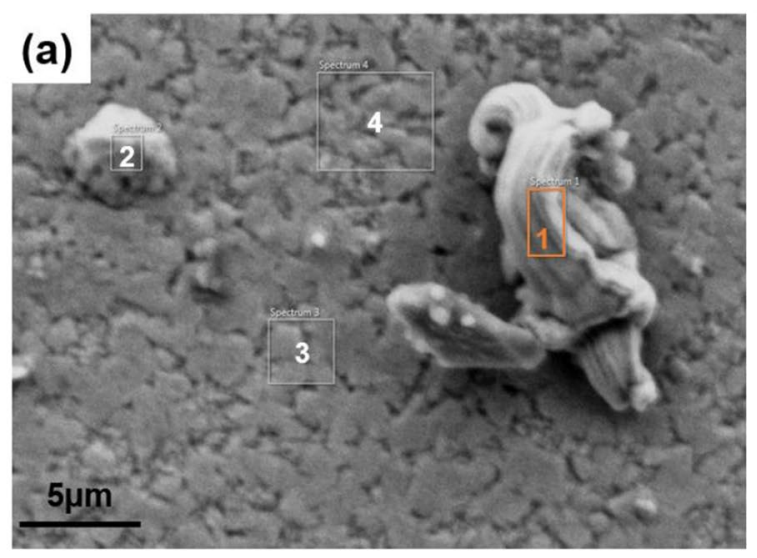

(c)
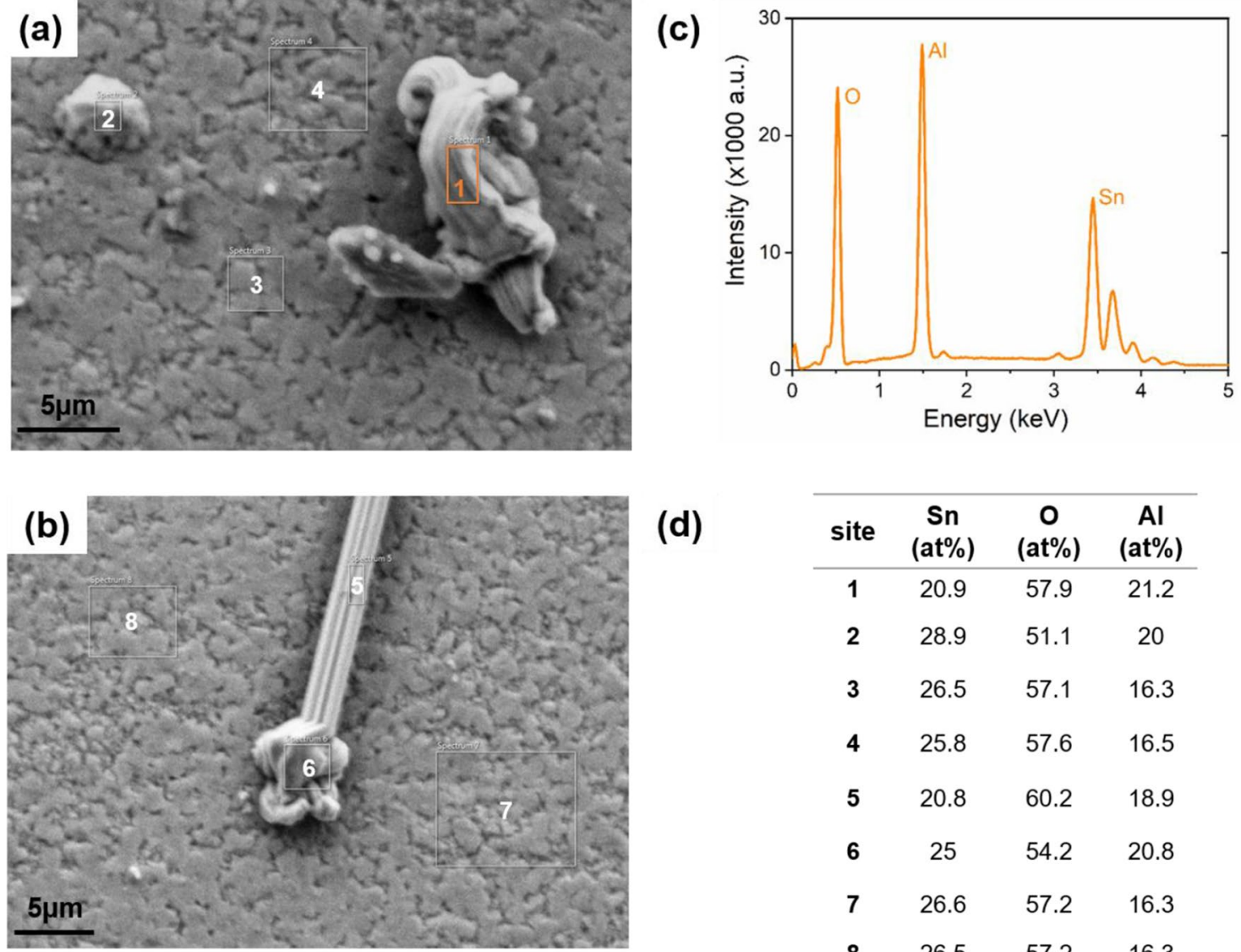

(d)

\begin{tabular}{cccc}
\hline site & $\begin{array}{c}\text { Sn } \\
\text { (at\%) }\end{array}$ & $\begin{array}{c}\text { O } \\
\text { (at\%) }\end{array}$ & $\begin{array}{c}\text { Al } \\
\text { (at\%) }\end{array}$ \\
\hline $\mathbf{1}$ & 20.9 & 57.9 & 21.2 \\
$\mathbf{2}$ & 28.9 & 51.1 & 20 \\
$\mathbf{3}$ & 26.5 & 57.1 & 16.3 \\
$\mathbf{4}$ & 25.8 & 57.6 & 16.5 \\
$\mathbf{5}$ & 20.8 & 60.2 & 18.9 \\
$\mathbf{6}$ & 25 & 54.2 & 20.8 \\
$\mathbf{7}$ & 26.6 & 57.2 & 16.3 \\
$\mathbf{8}$ & 26.5 & 57.2 & 16.3 \\
\hline
\end{tabular}

Fig. 4 EDX elemental analysis of whiskers grown on an ALD-coated sample. a, b Secondary scanning electron images of different whiskers and nodules on ALD-coated test coupons, having 15 days delay before the ALD coating. EDX measurement sites are labelled accordingly. c EDX spectrum at site 1 in micrograph (a) showing large

of ALD coating failure. After 200 cycles, only one sample with a pre-coat time of 15 days showed whisker growth. However, in this case, the whisker density was $\sim 50$ whiskers/ $\mathrm{cm}^{2}$, which is lower than the value initially measured for the sample. This suggests that no increase in whisker density has occurred as a result of thermal cycling in the first few weeks.

\subsection{Storage time under different environmental conditions}

Test coupons belonging to the set of experiments in Figs. 1 and 3 were further analyzed after being stored either at room temperature or in a controlled environment $\left(55^{\circ} \mathrm{C} / 85 \% \mathrm{RH}\right)$ (one test coupon each). Figure 5 shows our preliminary results on the effect of storage time on the overall whiskers density of un-coated tested coupons in the case of roomtemperature storage. As our collection of samples has been measured after different time intervals, we have studied these effects in terms of whisker density normalized increase signal coming from $\mathrm{Sn}, \mathrm{Al}$, and $\mathrm{O}$, suggesting that the whisker was already on the surface prior to ALD coating (see manuscript form more details). d Summary of elemental composition for different measured sites as labelled in (a) and (b)

(percentage) and normalized storage time, where day " 0 " is the first time a whisker count has been carried out. This will enable us to make a more objective comparison between our samples. Our findings shows that neither storage time nor storage conditions (at elevated temperature/humidity, not shown) had any effect on ALD-coated samples, which did not show any whiskers in both cases. Also, the sample for which ALD coating was performed about 15 days after the electroplating showed no major difference in whisker density (negligible variations are most likely due to different sampling areas for each whisker density measurement).

Figure $5 \mathrm{a}, \mathrm{b}$ refers to the same reference test coupons reported in Figs. 1 and 3, respectively. As expected, uncoated test coupons showed a progressive increase in whisker density in all cases, with a slightly larger increase for the sample in Fig. 5a. All samples are currently undergoing a long-term study to assess if any correlation exists between whiskers density and storage time, which will be reported later on. In summary, we observed the following: 


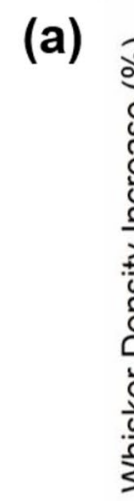

(b)

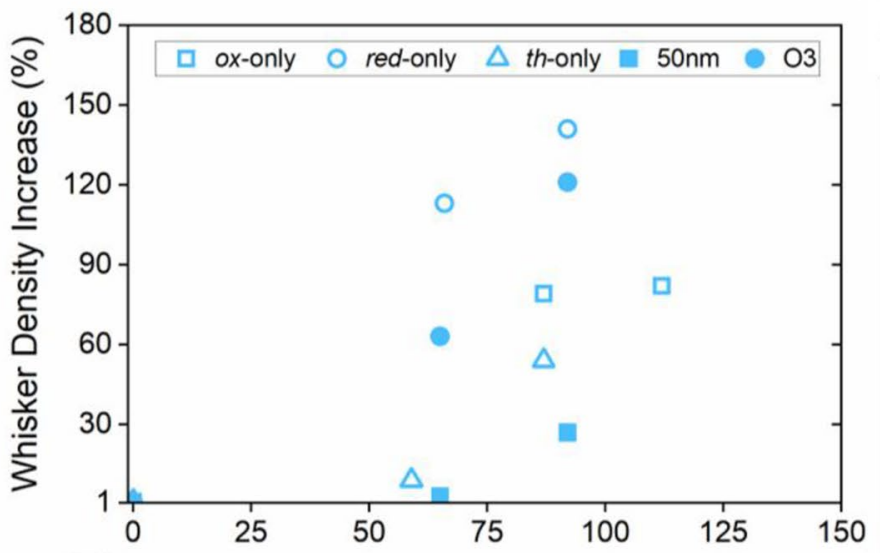

(c)
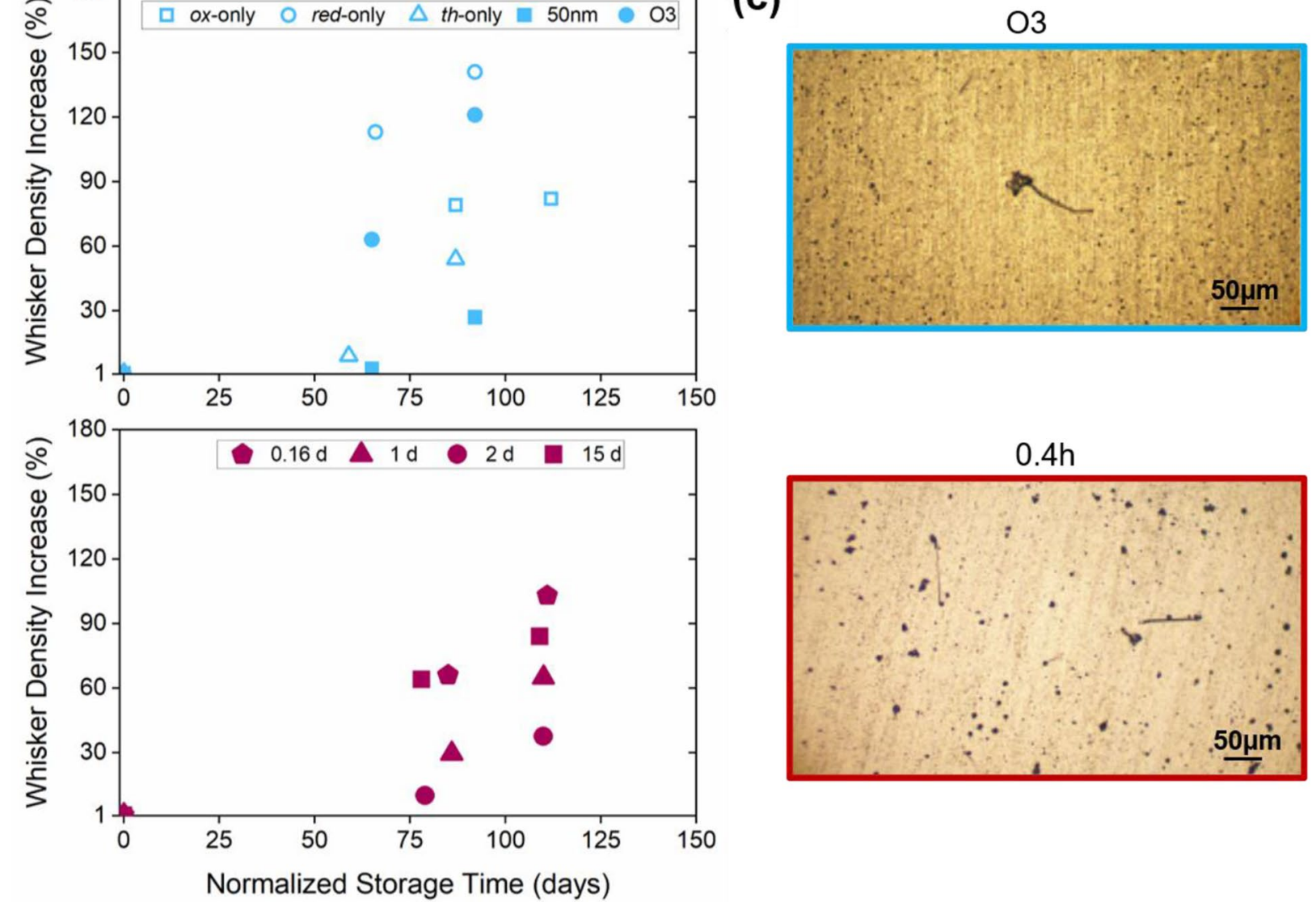

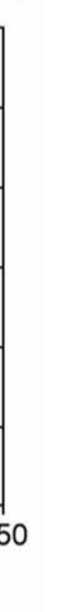

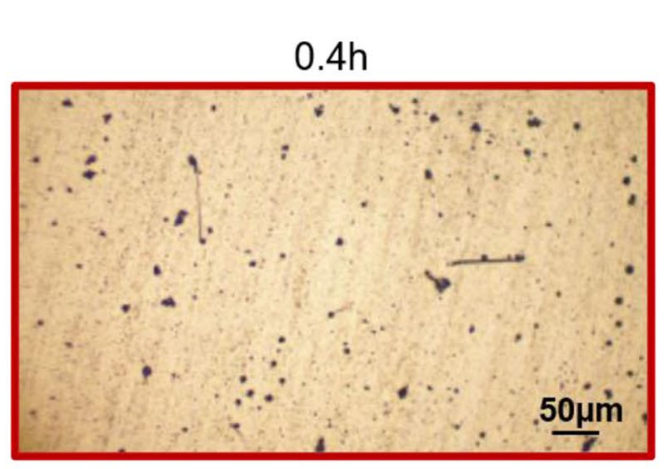

Fig. 5 Effect of storage time on whisker growth on un-coated test coupons at room temperature. a, b Relative whisker density increases (with respect to the first measurement) as a function of room-temperature storage time un-coated tested coupons from a Fig. 1 and $\mathbf{b}$ Fig. 3, respectively. c Optical images of representative samples from

i. Whiskers with lengths greater than $500 \mu \mathrm{m}$ were found more frequently in the un-coated samples (not shown);

ii. Morphology of the whiskers also differed, depending on the sample conditions, as shown in the optical images in Fig. 5c, for which a mixture of large eruptions and larger diameter whiskers has been found.

\subsection{ALD-coated printed circuit board assemblies' rework}

ALD-coating effectiveness against tin whisker growth has been tested on non-space grade PCBAs, manufactured by ENICS AG (Switzerland) containing components, using $\mathrm{Pb}$-free commercial solder alloys (solder alloy SAC305, $96.5 \% \mathrm{Sn}, 3.0 \% \mathrm{Ag}, 0.5 \% \mathrm{Cu}$ ). It is unlikely that large numbers of tin whiskers would be spontaneously grown on (a) and (b). Given the large collection of samples, our whisker counts are analyzed in terms of percentage increase and normalized storage time. ALD-coated samples do not show any new whisker growth (or increase in previously noted pre-ALD growth), independently of their process conditions

this assembly in ambient conditions in the short time since manufacture. An essential requirement for space applications is that the board be reworkable (to change components after manufacture, made by RUAG Space Finland Oy $\mathrm{Ab}$, without the need to remove the previously deposited ALD layer) and then to be recoated. For a single, reworked sample, X-ray fluorescence (XRF) was used to ensure that there was an ALD film on the reworked samples. Although $\mathrm{XRF}$ is not strictly a surface sensitive technique such as X-ray photoelectron spectroscopy (XPS), it nevertheless allowed us to qualitatively analyze our samples without the need to section the board as presented in Fig. 6 . Locations where the XRF point analysis has been carried out the PCB are shown in Fig. 6a, while Fig. 6b shows the XRF spectra acquired at $10 \mathrm{kV}$ at those locations, Panel (c) presents higher magnification images of the measurement sites. All acquired spectra present a small Al peak at $\sim 1.5 \mathrm{keV}$, independently of the site measurement, thus 


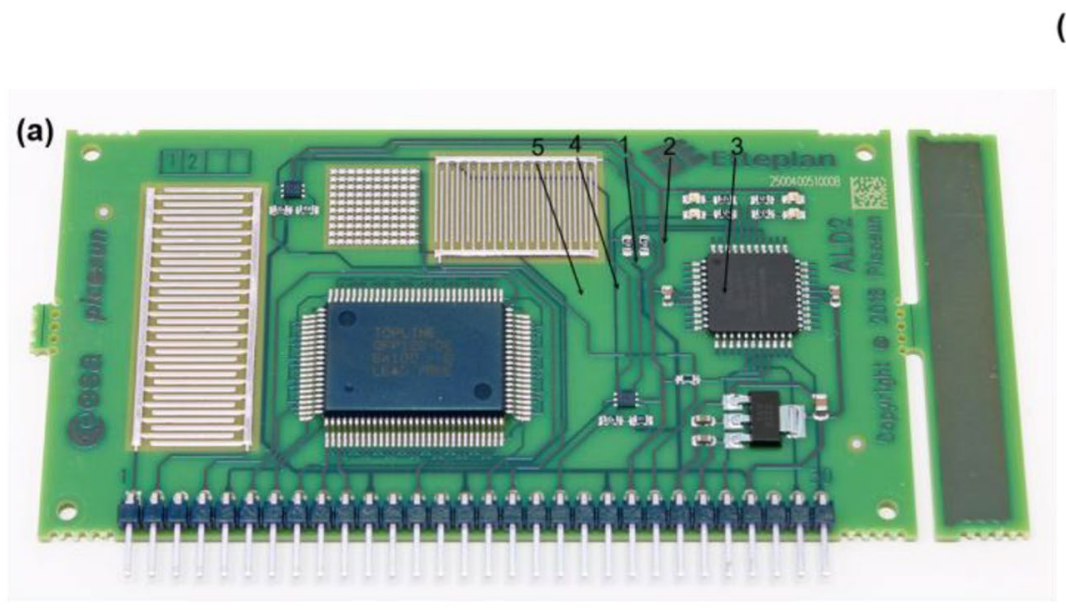

(c)

(b)
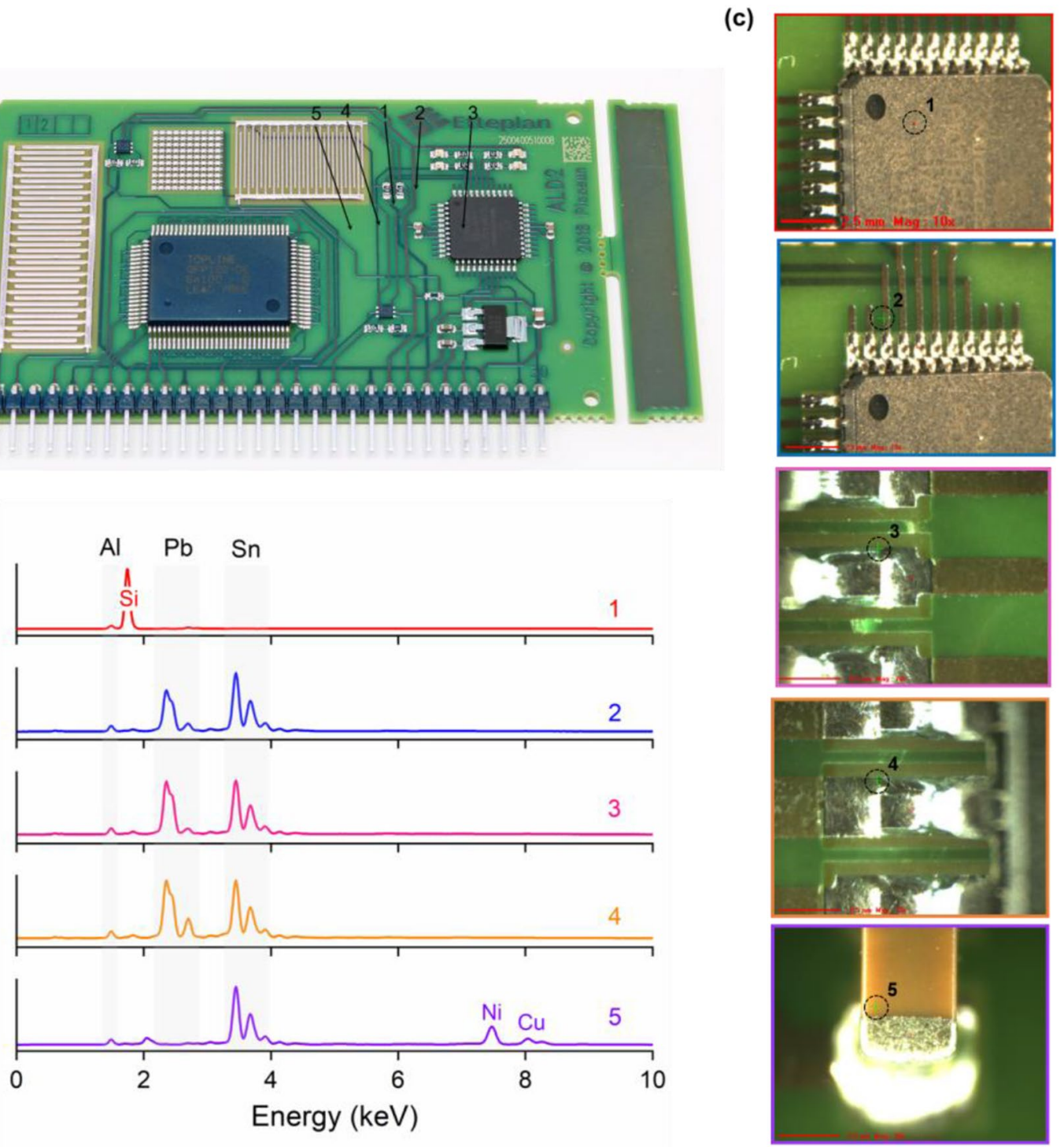

Fig. 6 X-ray fluorescence (XRF) study of ALD-coated PCBA. a Optical image of an ALD-coated PCBA with measurement site locations labelled. b XRF spectra at these locations with $\mathbf{c}$ corresponding

confirming the successful coating with the ALD process (alumina in this case).

\subsection{Bake-out test of ALD-coated PCBs}

Outgassing is an important issue in several applications in aerospace, especially with optical instruments on satellites; in fact, vapors often trapped in porous materials are drawn out in vacuum and ultra-high-vacuum condition (as in space) and can condense on nearby surfaces. This has been found to interfere with instruments, contaminate measurements, and affect overall correct functioning of equipment. Other detrimental effects include, e.g., the popcorn effect known for plastic packaging occurring during rapid expansion in the higher magnification optical images of the measurement sites. All the sites show $\mathrm{Al}$ on the board and components after rework and recoating

soldering process. Outgassing can be minimized by heating the materials in vacuum prior to use, a process often called "bake-out" (see ECSS-Q-ST-70-01C, cleanliness, and contamination control). For more details on the experimental set-up used in our experiments, we refer the reader to the Experimental section.

Our aim was to assess the effect of ALD on outgassing for PCBA (along with tin whisker mitigation), thus making ALD a technique suitable for space applications. After cleaning, PCBs (ALD-coated and un-coated) were placed on a hot plate $\left(T=100{ }^{\circ} \mathrm{C}\right)$ in the vacuum chamber and two quartz control monitors (QCMs) were used to measure any outgassed compounds. The QCM frequency is assumed to be proportional to the mass of outgassed material deposited 
on the QCM crystals. Figure 7 shows one representative PCB placed in the test chamber as well as the experimental results of the outgassing test carried out an un-coated PCB, an ALD-coated PCB (ALD11, coating thickness $\sim 80 \mathrm{~nm}$ ), and a blank sample (acting as a baseline). We have adopted ESTEC (European Space Research and Technology Centre) bake-out criteria, according to which we considered and measured the deviation from linearity of the QCM frequency rate as a function of time. We defined time $\tau$ when
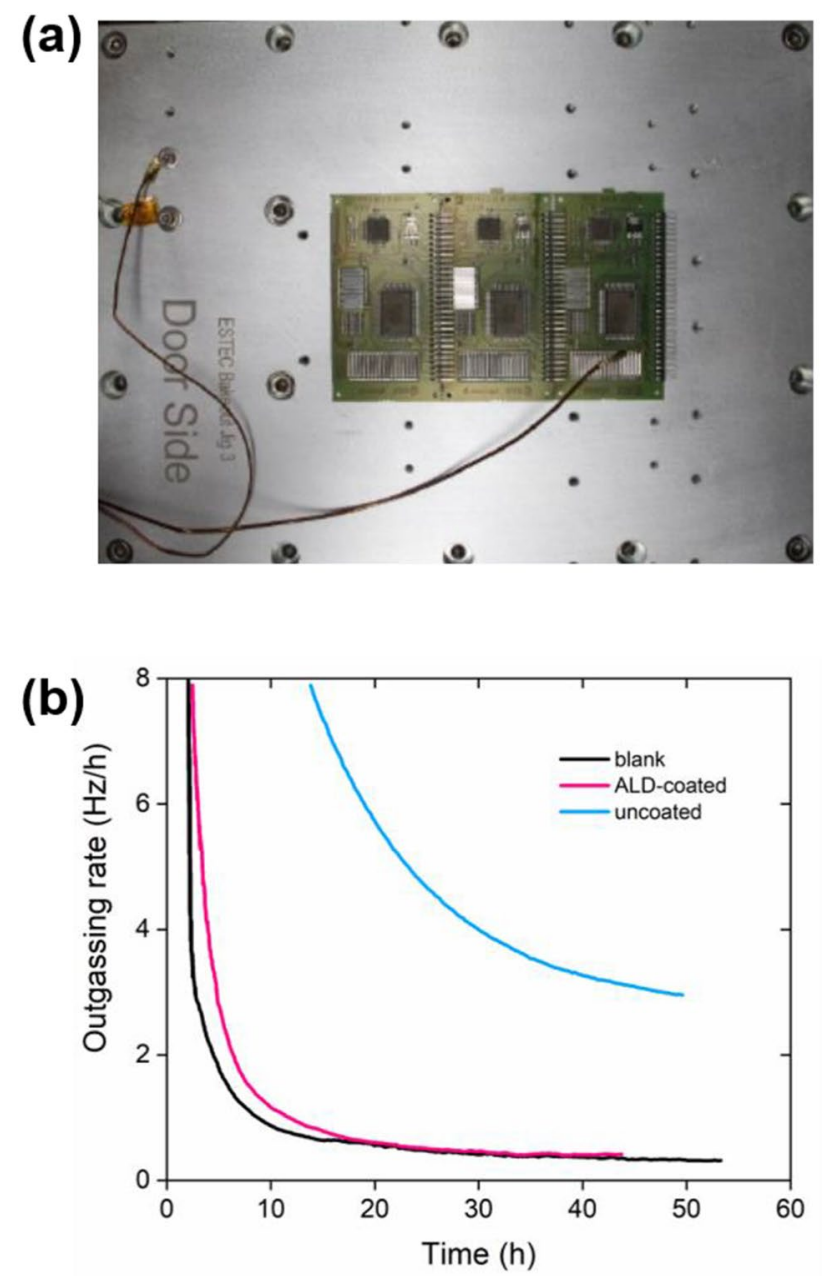

\begin{tabular}{ccc}
\hline (c) & $\begin{array}{c}\text { T } \\
\text { (h) }\end{array}$ & $\begin{array}{c}\text { outgassing rate } \\
(\mathrm{Hz} / \mathrm{h})\end{array}$ \\
\hline blank & 48 & 0.4 \\
uncoated & 41.8 & 3.1 \\
ALD-coated & 31.8 & 0.4 \\
\hline
\end{tabular}

Fig. 7 Bake-out test for ALD-coated PCB. a Optical image of a representative $\mathrm{PCB}$ in the bake-out test-chamber. b, $\mathbf{c}$ Outgassing rate as function of time and $\mathbf{c}$ extrapolated values for a blank sample (black), an un-coated (blue), and an ALD-coated (pink) PCBs this deviation was less than $1 \%$ per hour. Figure $7 \mathrm{~b}$ shows the isothermal time evolution of the outgassing rate to reach deviation from linearity less than $1 \%$ (indicated by arrows and reported in Fig. 7c). We found that un-coated samples had an outgassing rate of $3.1 \mathrm{~Hz} / \mathrm{h}$ and ALD-coated sample shows an outgassing rate similar to the blank sample $(0.4 \mathrm{~Hz} / \mathrm{h})$, which is almost an order of magnitude less than the reference un-coated sample. This demonstrates that ALD coating can effectively reduce the outgassing potential of PCBs used in space missions.

\section{Conclusions}

In this work, we have demonstrated how ALD-deposited conformal coatings can be exploited as an effective approach to mitigate whisker growth and outgassing on printed circuit board assemblies. By combining optical and scanning electron microscopy, we have evaluated whisker distributions on the surface of more than $100 \mathrm{Sn}-\mathrm{Cu}$-electroplated test coupons over a period of more than 2 years and we addressed the influence of different ALD coating parameters on electroplated test coupons (ALD process steps, pre-coat time, thickness, and storage time under different conditions). We found that:

i. Pre-coat time (interval between electroplating and ALD processes) plays a central role in determining the extent of whisker growth, with pre-coat times shorter than 2 days being more effective, since whisker initiation has yet to occur;

ii. ALD coating prevents whisker growth in the case of elevated temperature/humidity, thermal cycling, and storage in different environmental conditions (room temperature, $55{ }^{\circ} \mathrm{C} / 85 \% \mathrm{RH}$ );

iii. In the absence of an ALD coating, all un-coated test coupons show a gradual increase in whisker density with time.

In addition, ALD coatings are also capable of drastically reducing outgassing in PCBAs, thus rendering atomic layer deposition a suitable technique to prevent tin whisker growth in assemblies relevant for aerospace applications.

Investigation of long(er) term effects of ALD coatings is currently ongoing both on test coupons and PCBAs. Future plans to gain further insight on tin whisker formation and atomic layer deposition, include:

- a more detailed investigation on the effect of pre-coat time to identify a potential threshold for the initiation of whisker growth (expected to be between 2 and 15 days);

- cross-sectional transmission electron microscopy (TEM) studies of whiskers growth on ALD-coated and un-coated 
coupons, to potentially identify the underlying mechanism behind whisker growth and to possibly attribute it to any of the mechanisms described in the current paper;

- a study of the effect of storage time and condition on whisker length, where the study, to be quantitative, will require imaging of the same area repeatedly within the same test coupon;

- ALD process parameters, where coating and corresponding fabrication steps have not been optimized. Parameters such as coating thickness, chamber pressure, growth temperature, and precursors' type (if oxidizing or not) might indeed play a role in the effectiveness of the coating itself;

- PCBA surface finishes and solder alloys, which might affect both tin whisker formation as well as degassing.

Acknowledgements The majority of the work was financed by ESA project "Atomic Layer Deposition for Tin Whiskers Mitigation and Cure on Space Electronics Manufacturing" 4000122745/18/NL/LvH/ gp. The authors also acknowledge use of facilities within the Loughborough Materials Characterisation Centre, UK. CS acknowledges the support from the Academy of Finland Flagship Program (Grant No.: 320167, PREIN) and support from Aalto Seed funding scheme. The authors wish to thank Adrian Tighe and Abel Brieva from ESA/ESTEC for providing information about the bake-out measurements.

Funding Open access funding provided by Aalto University.

\section{Declarations}

Conflict of interest The authors declare no conflict of interest.

Open Access This article is licensed under a Creative Commons Attribution 4.0 International License, which permits use, sharing, adaptation, distribution and reproduction in any medium or format, as long as you give appropriate credit to the original author(s) and the source, provide a link to the Creative Commons licence, and indicate if changes were made. The images or other third party material in this article are included in the article's Creative Commons licence, unless indicated otherwise in a credit line to the material. If material is not included in the article's Creative Commons licence and your intended use is not permitted by statutory regulation or exceeds the permitted use, you will need to obtain permission directly from the copyright holder. To view a copy of this licence, visit http://creativecommons.org/licenses/by/4.0/.

\section{References}

1. Suganuma, K., Baated, A., Kim, K.-S., Hamasaki, K., Nemoto, N., Nakagawa, T., Yamada, T.: Acta Mater. 59(19), 7255-7267 (2011)

2. https://ec.europa.eu/environment/topics/waste-and-recycling/rohsdirective_it

3. https://www.calrecycle.ca.gov/electronics/act2003

4. JEDEC.: JESD22-A121A: test method for measuring whisker growth on tin and tin alloy surface finishes (2008)

5. Osterman, M.: 6th International Symposium Tin Whiskers, Henry Ford College, Loughborough (2012)
6. Brusse, J.A., Ewell, G.J., Siplon, J.P.: Cart. 2002 22nd Capacitor and Resistor Technology Symposium, New Orleans, p. 67 (2002)

7. Tu, K.N., Li, J.C.M.: Mater. Sci. Eng. A 409, 131-139 (2005)

8. Tu, K.N., Chen, C., Wu, A.T.: J. Mater. Sci. Mater. Electron. 18, 269-281 (2007)

9. Chason, E., Jadhav, N., Pei, F., Buchovecky, E., Bower, A.: Prog. Surf. Sci. 88, 103-131 (2013)

10. Tu, K.N.: Phys. Rev. B 49, 2030-2034 (1994)

11. Chason, E., Jadhav, N., Chan, W.L.R.L., Kumar, K.S.: Appl. Phys. Lett. 92, 171901 (2008)

12. Illes, B., Skwarek, A., Ratajczak, J., Dusěk, K., Busěk, D.: J. Alloy. Compd. 785, 774-780 (2019)

13. Chason, E., Pei, F., Jain, N., Hitt, A.: J. Electron. Mater. 48, 17-24 (2019)

14. Illes, B., Horvath, B., Geczy, A., Krammer, O., Dusěk, K.: Solder. Surf. Mt. Technol. 29, 59-68 (2017)

15. Mahim, Z., Ismail, N.A., Salleh, M.A.A.M., Khor, C.Y.: Solid State Phenom. 280, 194-199 (2018)

16. Lin, Y.W., Lai, Y.S., Lin, Y.L., Tu, C.T., Kao, C.R.: J. Electron. Mater. 37, 17-22 (2008)

17. Illes, B., Hurtony, T., Medgyes, B.: Corros. Sci. 99, 313-319 (2015)

18. Karpov, V.G.: Phys. Rev. Appl. 1(1), 044001 (2014)

19. Osenbach, J.W.: J. Appl. Phys. 106, 094903 (2009)

20. Winterstein, J.P., Norton, M.G.: J. Mater. Res. 21, 2971-2974 (2006)

21. Murakami, K., Okano, M., Hino, M., Takamizawa, M., Nakai, K.: Mater. Trans. Jpn. Inst. Met. 51, 143-151 (2010)

22. Han, S., Osterman, M., Meschter, S., Pecht, M.: J. Electron. Mater. 41, 2508-2518 (2012)

23. Hunt, C., Wickham, M.: International Symposium on Advanced Packaging Materials.: Microtech (APM), 78-87 (2010)

24. Kadesch, J.S., Leidecker, H.: Proc. of the 37th IMAPS Nordic Annual Conf., 108-116 (2000).

25. Wickham, M.: "New results from National Physics Laboratory Whiskers Study" EMPS-10, Electronic Materials and Processes for Space (2019)

26. Ortigoza-Diaz, J., Scholten, K., Larson, C., Cobo, A., Hudson, T., Yoo, J., Baldwin, A., Hirschberg, A.W., Meng, E.: Micromachines 9(9), 422 (2018)

27. Fortin, J.B., Lu, T.-M.: Kluwer Academic Publishers, Norwell (2004)

28. Hillman, D., Wilcoxon, R., Lower, N., Grossman, D.: J. Electron. Mater. 44, 4864-4883 (2015)

29. Napari, M., Lahtinen, M., Veselov, A., Julin, J., Østreng, E., Sajavaara T.: Surf. Coat. Technol. 326(Part A), 281-290 (2017)

30. Hu, L., Qi, W., Li, Y.: Nanotechnol. Rev. 6(6), 527-547 (2017)

31. Carcia, P.F., McLean, R.S., Groner, M.D., Dameron, A.A., George, S.M.: J. Appl. Phys. 106, 023533 (2009)

32. Li, Y., Xiong, Y., Yang, H., Cao, K., Chen, R.: J. Mater. Res. 35, 681-700 (2020)

33. Härkönen, E., Diaz, B., Swiatowska, J., Maurice, V., Seyeux, A., Vehkamäki, M., Sajavaara, T., Fenker, M., Marcus, P., Ritala, M.: J. Electrochem. Soc. 158, C369-C378 (2011)

34. Johnson, R.W., Hultqvist, A., Bent, S.F.: Mater. Today 17, 236246 (2014)

35. Ashworth, M.A., Wilcox, G.D., Higginson, R.L., Heath, R.J., Liu, C., Mortimer, R.J.: Microelectron. Reliab. 55, 180-191 (2015)

36. JESD22-A104D, https://www.jedec.org

37. Kutilainen, T., Pudas, M., Ashworth, M.A., Lehto, T., Wu, L., Wilcox, G.D., Wang, J., Collander, P., Hokka, J.: J. Electron. Mater. 48, 7573-7584 (2019)

38. Fukuda, Y., Osterman, M., Pecht, M.: Microelectron. Reliab. 47(1), 88-92 (2007)

39. Kim, J.B., Kwon, D.R., Chakrabarti, K., Lee, C.: J. Appl. Phys. 92, 6739-6742 (2002) 
40. Park, J.-S., Chae, H., Chung, H.K., Lee, S.I.: Semicond. Sci. Technol. 26, 034001 (2011)

41. Walsh, F.C., Low, C.T.J.: Surf. Coat. Technol. 304, 246-262 (2016)

42. Hou, L., Moelans, N., Derakhshandeh, J., De Wolf, I., Beyne, E.: Sci. Rep. 9, 14862 (2019)

43. Herkommer, D., Punch, J., Reid, M.: Microelectron. Reliab. 50(1), 116-126 (2010)
44. Lee, T.K., Zhou, B., Blair, L., Liu, K.-C., Bieler, T.R.: J. Electron. Mater. 39(12), 2588-2597 (2010)

Publisher's Note Springer Nature remains neutral with regard to jurisdictional claims in published maps and institutional affiliations. 